\title{
Isolation and Elucidation of 15-Acetylguanacone from Soursop (Annona muricata Linn) Fruit and Molecular Docking Experiments
}

\section{${ }^{1}$ AGU, KINGSLEY CHUKWUNONSO $;{ }^{2}$ OKOLIE, NGOZI PAULINUS; ${ }^{3}$ FALODUN, ABIODUN; ${ }^{3}$ ERHARUYI, OSAYEMWENRE; ${ }^{4}$ IGBE, IGHODARO; ${ }^{5}$ ELEKOFEHINTI, OLUSOLA OLALEKAN; ${ }^{1}$ EDOSA, RICHARD OSARO; IOGHAGBON, STEPHEN EWEMADE.}

\author{
${ }^{2}$ Department of Biochemistry, Faculty of Life Sciences, University of Benin. \\ ${ }^{3}$ Department of Pharmaceutical Chemistry, Faculty of Pharmacy, University of Benin. \\ ${ }^{4}$ Department of Pharmacology and Pharmacognosy, Faculty of Pharmacy, University of Benin. \\ ${ }^{5}$ Department of Biochemistry, Adekunle Ajasin University, Ondo state. \\ Correspondence: ${ }^{I}$ Kingsley Chukwunonso AGU, PhD. Department of Medical Biochemistry, \\ School of Basic Medical Sciences, College of Medical Sciences, 300001, University of Benin. \\ Email: chukwunonso.agu@uniben.edu.Phone: +234(0)8035657035.
}

\begin{abstract}
Annona muricata (Soursop) has attracted attention due to its content of annonaceous acetogenins, a large family of naturally occurring polyketides isolated from various species of the genus Annonaceae. The ethyl acetate fraction of Annona muricata was subjected to standard isolation protocol-gradient and isocratic silica gel column chromatography- to obtain three waxy and whitish amorphous compounds, 002/A1, 002/A2 and $002 / \mathrm{C}$. The structure of compound 200/A2 was elucidated using ${ }^{1} \mathrm{H}-\mathrm{NMR}$ spectroscopy, infrared spectroscopy and electron impact (EI+) mass spectroscopy. The molecular weight of 200/A2 was determined as 662 by EI-MS $\left([\mathrm{M}+\mathrm{H}]^{+}: \mathrm{m} / z=662.1\right)$ leading to the molecular formula $\mathrm{C}_{39} \mathrm{H}_{66} \mathrm{O}_{8}$ as obtained using high resolution MS. The existence of an $\alpha, \beta$-unsaturated $\gamma$-lactone moiety, non-hydroxylated at the C-4 position, was suggested by an IR carbonyl absorption at $1735.9 \mathrm{~cm}^{-1}$ and $1662.7 \mathrm{~cm}^{-1}$; the IR also gave signal for hydroxyl group at $3339.0 \mathrm{~cm}^{-1}$. The presence of a characteristic vinyl proton $\delta 7.24(\mathrm{H}-35, \mathrm{~d})$, which is characteristic for $\alpha, \beta$ unsaturated $\gamma$-lactone was confirmed by the 1H-NMR spectrum. The compound was thus elucidated to be 15-acetyl guanacone, an acetogenin. This acetogenin has not been reported in Annona muricata previously. The compound was subsequently subjected to molecular docking experiments which revealed that it targets and binds to vascular endothelial growth factor 2 , VEGF2 $(-8.5 \mathrm{kcal} / \mathrm{mole})$ and $\alpha 1 \beta 2$ integrin $(-6.8 \mathrm{kcal} / \mathrm{mole})$, This thus suggests that 15 -acetyl guanacone prevents metastasis and invasion by cancer cells, and ultimately initiates apoptosis. (C) JASEM
\end{abstract}

\section{https://dx.doi.org/10.4314/jasem.v21i2.3}

Key words: VEGF2; Integrin; Cancer; Acetogenins; Apoptosis; Soursop.

Annonaceous acetogenins (ACG) are potent bioactive secondary metabolites, long-chain fatty acids derivatives possessing a terminal $\alpha, \beta$-unsaturated $\gamma$-lactone ring, a mono- or bis-tetrahydrofuran (THF) moiety found primarily in the Annonaceae family to which Annona muricata (Soursop) belongs (Barrachina et al., 2007), and have been proven to possess potent in vivo and in vitro anticancer activities (Bermejo et al., 2005; Kojima et al., 2009; Oberlies et al., 1997a; Oberlies et al., 1997b). Some of the modes by which they carry out anticancer actions has been reported to include the inhibition of NADH-ubiquinone oxidoreductase (complex I) in mitochondria, inhibition of both P-glycoprotein pump (used by resistant cancer cells) and NADH oxidase (Morré et al., 1995; Gupta et al., 2011), depleting ATP (adenosine triphosphate), especially for cancer cells with high metabolic levels, leading to apoptosis. Amongst the reported acetogenin is the guanacone acetogenin, a 10-keto bis-tetrahydrofuran compound (Barrachina et al., 2007; Gallardo et al., 1998) that was initially isolated from Annona spraguei Saff. Seeds and elucidated. However, we subjected the ethyl acetate fruit extract of Soursop to standard isolation scheme and then subsequently elucidated and characterised the isolated compound using spectroscopic techniques; we further subjected the compound to molecular docking experiments to identify potential targets in its anticancer principle. 


\section{MATERIALS AND METHOD}

Isolation of compound using Column Chromatography: The methanolic extract of Annona muricata fruit pulp (18g) was subjected to silica gel fractionation using sintered funnel-vacuum-pump (vacuum-liquid, VLC) fractionation; the solvent mixtures included hexane, Hex (100\%), hexane-ethyl acetate (50-50\%), ethyl acetate, EA (100\%), ethyl acetate-methanol (50-50\%), methanol, $\mathrm{MeOH}$ $(100 \%)$ and methanol-water (90-10\%). Five (5) gram of the EA-VLC fraction was further subjected to gradient column chromatographic fractionation on silica gel (EDWC, 60-120 mesh). Column ( $2 \mathrm{~cm} \times 40$ $\mathrm{cm}$ ) was set up in hexane (Hex), ethyl acetate (EA) and methanol (MeOH) with silica gel (35 to $40 \mathrm{~g}$ ) and eluted with gradients of solvents from 100:0:0\% to $0: 100: 0 \%$ and to $0: 0: 100 \%$ of Hex: EA: $\mathrm{MeOH}$. The fractions were collected into 208 test tubes, bulked together based on similar Rf values on TLC plates and allowed to dry under ambient room temperature. The bulked test tube fractions 83 to 96 was again subjected to isocratic column chromatography, as it was observed that whitish amorphous substance was being precipitated on the walls of the test tubes and gave three spots on TLC, giving rise to an impure amorphous substance, 002/A. This obtained substance was subjected to preparative TLC separation to obtain the pure compounds 002/A1 (0.018g), 002/A2 (0.032g) and $002 / \mathrm{C}(0.012 \mathrm{~g})$. Due to the amounts of pure compounds, only 002/A2 was subjected to spectroscopy for structure elucidation and characterization.

Proton Nuclear Magnetic Resonance ( $\left.H^{I} N M R\right)$ spectroscopy: The sample was dissolved in $\mathrm{CDCL}_{3}$. The different functional groups based on proton association were identified using NMR (JNMPMX60SI) at 500MHz.

Infrared (IR) Spectroscopy: Using Perkin-Elmer 1430 infrared spectrophotometer, the functional groups of the compound was identified. The measurements were carried out at infra-red spectra between 400 to $4000 \mathrm{~nm}$.

Electron Impact+ Mass Spectra (MS): A mass spectrophotometer (MS-600H-1) was used. The product was subjected to a steam of high energy of electrons at elevated temperature up to $100^{\circ} \mathrm{C}$ (vaporization, fragmentation and ionization). The cleavage fragments were yielded which were characterized by mass/charge from mass spectra data.
Molecular Docking Experiments, Protein preparation and Generation of 3-D structure using homology modelling: The starting structure (PDB ID: 4GL7) required for docking was retrieved from the protein data bank repository (http: //www.rcsb.org). Prior to docking, water and ligand coordinates were deleted. Vascular endothelial growth factor 2 (VEGF2) was downloaded from www.pubmed.org and used to model the starting structure of the elucidated compound used in the current study. Homology modelling was done on Swiss Model Server (http://swissmodel.expasy.org). This requires one sequence of known 3D structure with significant similarity with the target sequence. The co-ordinate file of template from protein data bank (PDB ID: 4GL7) was used to model the 3D structure of VEGF2

Ligand Preparation for Docking: The 3D structure of elucidated compound was built using Marvinsketch and optimized for docking studies. The optimized ligand molecules (the compound) was docked into refined aromatase model using "Ligand-Fit" in the Auto-Dock 4.2.

Molecular Docking: Molecular Docking calculations were performed through BSP-SLIM and Auto-dock. The modeled structures of VEGF2 and elucidated compound was loaded on BSP-SLIM server and Auto-dock/Vina and all the water molecules were removed prior to the upload. BSP-SLIM is known as a blind docking method, which primary uses the structural template match to identify putative ligand binding sites, followed by fine-tuning and ranking of ligand conformations in the binding sites through the SLIM-based shape and chemical feature comparisons (Gavanji et al., 2014).

Data Analysis: Protein snapshots were taken and analysed using PYMOL.

\section{RESULTS AND DISCUSSIONS}

The guiding principle of isolation is based on the established anticancer properties attributed to the Annonaceous acetogenins and some other important phytochemicals present in soursop (Annona muricata). A classical isolation and purification procedure was adopted. The ethyl acetate leaf (EAL) fraction was subjected to silica gel open column chromatography using a gradient solvent mixture (hexane-ethyl acetate-methanol). Test tubes 83 to 96 (5\% hexane: $95 \%$ ethyl acetate) precipitated an amorphous waxy substance that was latter subjected to isocratic column chromatography $(10 \%$ hexane: 90\% ethyl acetate) and preparative TLC separation (hexane: ethyl acetate, 7.5:2.5) procedures for 
separation after spotting on paper TLC revealed the presence of two (2) other compounds; 002/A1 $(0.018 \mathrm{~g}), 002 / \mathrm{A} 2(0.032 \mathrm{~g})$ and $002 / \mathrm{C}(0.012 \mathrm{~g})$ were obtained.

Isolates 002/A1 and 002/A2 were whitish amorphous waxy compounds, while $002 / \mathrm{C}$ was an orange colour oily compound. For isolate 002/A2, molecular weight was determined as 662 by EI-MS $\left([\mathrm{M}+\mathrm{H}]^{+}: \mathrm{m} / z=\right.$ 662.1) leading to the molecular formula $\mathrm{C}_{39} \mathrm{H}_{66} \mathrm{O}_{8}$. The existence of an $\alpha, \beta$-unsaturated $\gamma$-lactone moiety, non-hydroxylated at the $\mathrm{C}-4$ position, was suggested by an IR carbonyl absorption at $1735.9 \mathrm{~cm}^{-}$ 1 and $1662.7 \mathrm{~cm}^{-1}$; the IR also gave signal for hydroxyl group at $3339.0 \mathrm{~cm}^{-1}$ (figure 3 ). The presence of a vinyl proton $\delta 7.24(\mathrm{H}-35, \mathrm{~d})$, which is characteristic for $\alpha, \beta$-unsaturated $\gamma$-lactone was confirmed by the $1 \mathrm{H}-\mathrm{NMR}$ spectrum (figure 1). Also, signals that showed six more protons at $\delta 4.65, \delta$ $4.00, \delta 3.63, \delta 3.50 \mathrm{ppm}, \delta 2.33$ and $\delta 2.21$ were observed in the ${ }^{1} \mathrm{H}$-NMR spectrum. The integration of the ${ }^{1} \mathrm{H}-\mathrm{NMR}$ revealed the presence of three methyl groups and 24 methylene groups, with two protons, $2.21 \mathrm{ppm}$ and $2.34 \mathrm{ppm}$ integrating for the oxygenbearing carbons at $\mathrm{C}-15$ and $\mathrm{C}-24$ (figure 2). According to Bermejo et al. (2005), Alali et al. (1999) and Takada et al. (2000), acetogenins with molecular weight above 600 usually possess the bulky bis-tetrahydrofuran (THF) moiety, classified as either adjacent, non-adjacent or saturated lactone, which was confirmed by the fragmentation pattern of the MS spectra, $141 \mathrm{~m} / \mathrm{z}$ (figure 5).

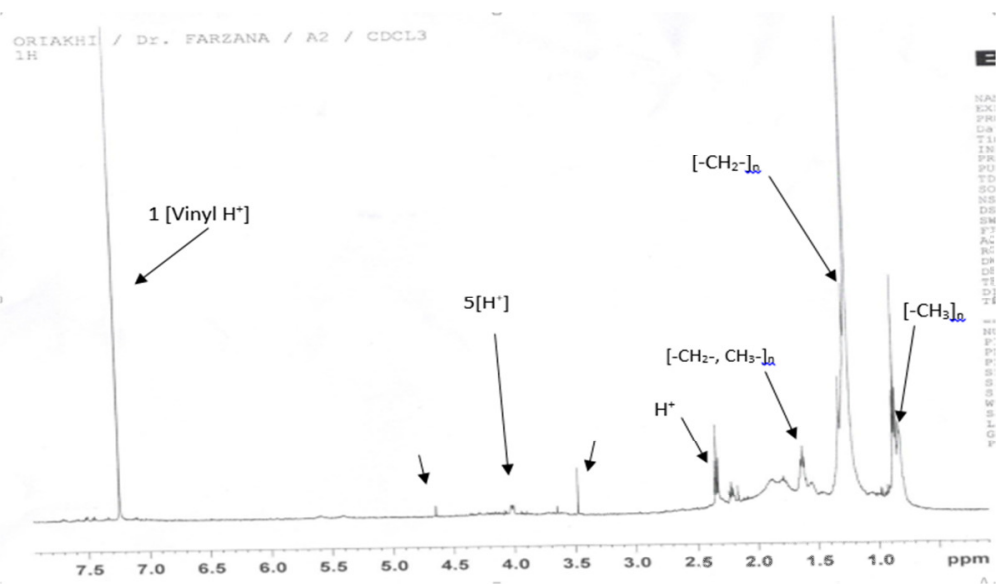

Fig 1: ${ }^{1} \mathrm{H}$ NMR spectra data of $002 / \mathrm{A} 2\left[\mathrm{CDCl}_{3}, 500 \mathrm{MHz}, \delta(\mathrm{ppm}), J(\mathrm{~Hz})\right]$ displayed above supports the presence of methylene, methyl groups, hydroxyl proton and a characteristic chemical shift signal (7.240ppm; $J=1.62 \mathrm{~Hz}$ ) for the vinyl proton (position 35 of the $\gamma$-lactone ring).

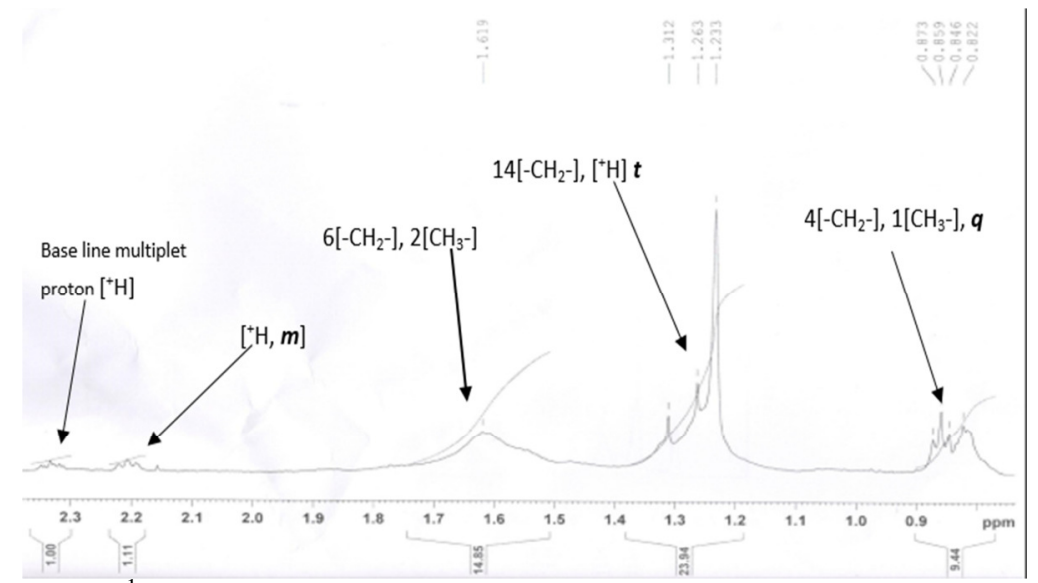

Fig 2: Integration of ${ }^{1} \mathrm{H}$ NMR spectra of 002/A2. The integration of the NMR spectra between $0.00 \mathrm{ppm}$ to 2.70ppm gave integrals of 1.0:1.11:14.85:23.94:9.44, thus integrating for 1:1:18:28:11 protons, i.e. $1\left[{ }^{+} \mathrm{H}\right]: 1\left[^{+} \mathrm{H}\right]: 18\left[6-\mathrm{CH}_{2^{-}}, \quad 2 \mathrm{CH}_{3^{-}}\right]: 29\left[14-\mathrm{CH}_{2^{-}},{ }^{+} \mathrm{H}\right]: 11\left[1 \mathrm{CH}_{3^{-}}, 4-\mathrm{CH}_{2^{-}}\right]$. Thus, there are 3 methyl and 24 methylene groups. The two (2) multiplets, $2.21 \mathrm{ppm}$ and $2.34 \mathrm{ppm}$ integrated for 1 proton each for the oxygenbearing carbons at $\mathrm{C}-15$ and $\mathrm{C}-24$.

KINGSLEY, CHUKWUNONSO AGU; NGOZI, PAULINUS OKOLIE; ABIODUN, FALODUN; 


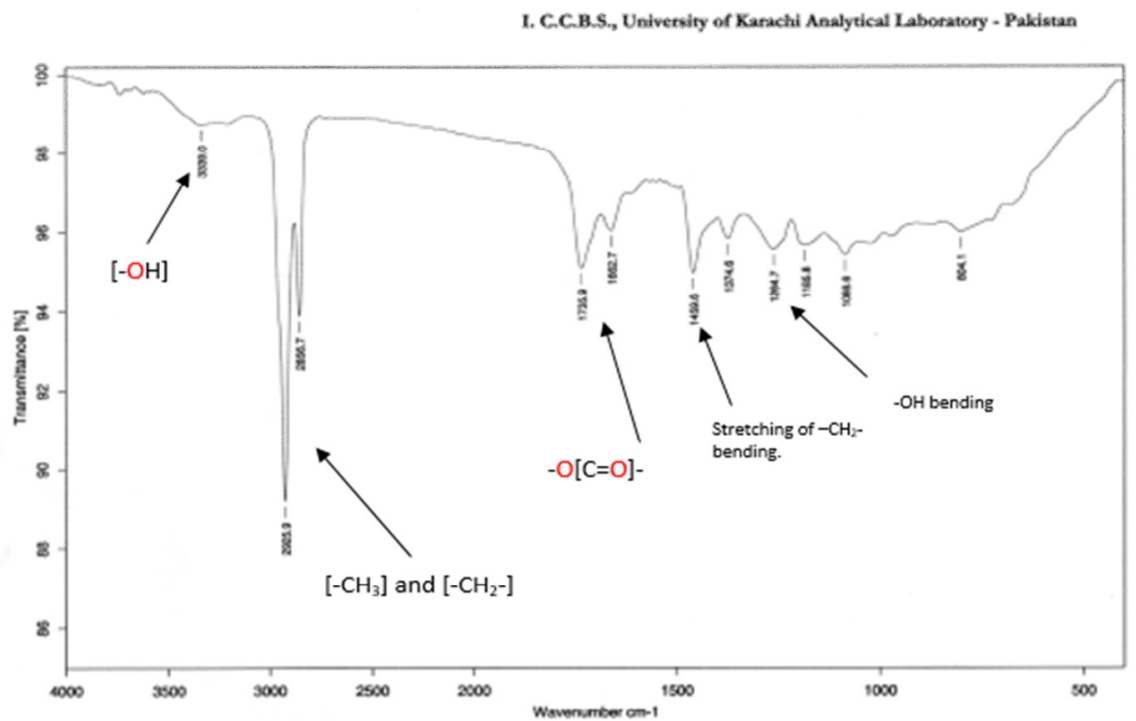

Fig 3: Infra-red (IR) spectra of 002/A2. The existence of $\alpha, \beta$-unsaturated $\gamma$-lactone moiety, non- hydroxylated at the $\mathrm{C}-4$ position, is suggested by an IR absorption by the carbonyl $(-\mathrm{O}[\mathrm{C}=\mathrm{O}]-)$ at $1735.9 \mathrm{~cm}^{-1}$ and $1662.7 \mathrm{~cm}^{-}$ 1 . The presence of hydroxyl functional group (-OH) is confirmed by IR absorption at $3339.0 \mathrm{~cm}^{-1}$

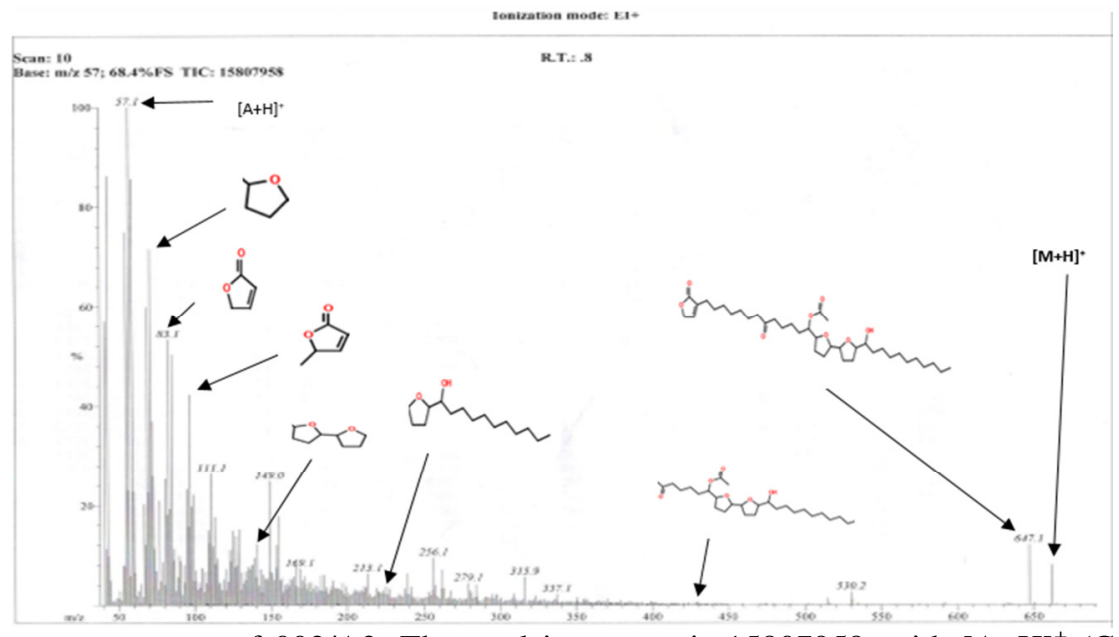

Fig 4: Mass spectroscopy of 002/A2. The total ion count is 15807958 , with $[\mathrm{A}+\mathrm{H}]^{+}\left(\mathrm{C}_{4} \mathrm{H}_{9}\right)$, being the most abundant ionized fragment $\left(\mathrm{m} / \mathrm{z}\right.$ 57). The molecular weight is determined by the EI-MS as $662\left([\mathrm{M}+\mathrm{H}]^{+}: \mathrm{m} / \mathrm{z}=\right.$ 662.1), thus arriving at a molecular formula of $\mathrm{C}_{39} \mathrm{H}_{66} \mathrm{O}_{8}$. Acetogenins with molecular weight above 600 usually possess the bulky bis-tetrahydrofuran (THF) moiety, classified as either adjacent, non-adjacent or saturated lactone. From the MS, this acetogenin has adjacent bis-THF. 


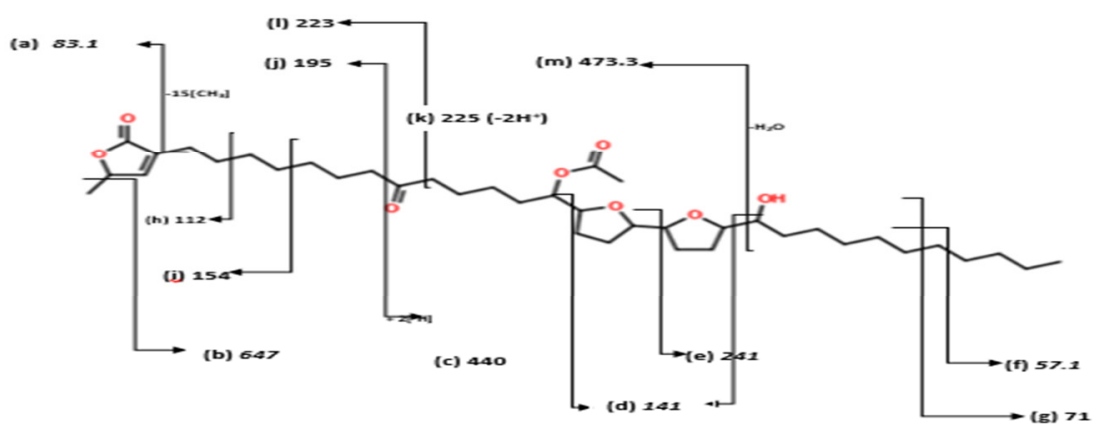

\begin{tabular}{|c|c|c|c|c|c|c|c|}
\hline EI- & $\mathbf{z}$ & b & $c$ & $d$ & e & $f$ & $\mathrm{~g}$ \\
\hline$\frac{(M 1+H)}{662}$ & $83.1(-[\mathrm{CH}])$ & 647 & $440(+2 \mathrm{H})$ & 141 & 241 & 57.1 & 71 \\
\hline FAB & $\frac{\mathrm{H}}{112}$ & $\frac{i}{154}$ & $\frac{j}{195}$ & $\frac{K}{225\left(-2 H^{\prime}\right)}$ & $\frac{1}{223}$ & $\frac{m}{473.3}$ & $\frac{n}{243\left(-2 \mathrm{H}^{\prime}\right)}$ \\
\hline
\end{tabular}

Fig5: Diagnostic E1-MS mass fragmentation ions of compound 002/A2.

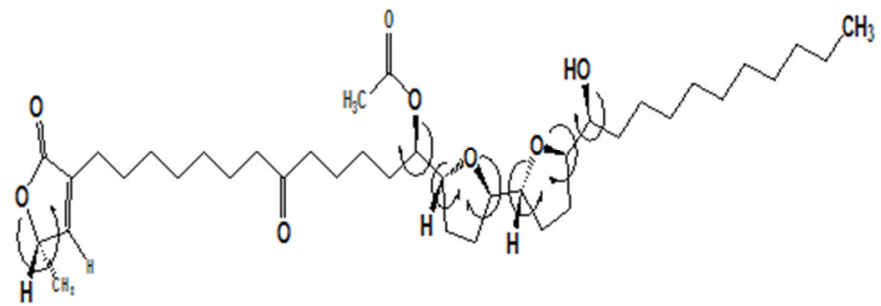

Fig 6: Relative stereochemical deduction of the structure of compound 002/A2 1 indicates stereochemistry (7 stereo-genic carbons or chiral centres), across the bis-THF skeleton from C-15 through C-24, and C-36, to be threo-trans-threo-trans-erythro configuration, as well as, R-S system of nomenclature (S, R, S, R, S, R and R). The chemical name of the compound is, acetic acid 1-[5'-(1-hydroxy-undecyl)-octahydro-[2, 2'] bifuranyl-5yl]-13-(5-methyl-2-oxo-2, 5-dihydro-

However, due to the limited amount of the compound, C13-NMR, COSY and NOESY were not carried out, but from the spectra obtained, along with the EI-MS ions fragmentation pattern of 002/A2, the structure of the compound was observed to be that of 15-acetylguanacone, as reported by Bermejo et al. (2005), with seven stereo-genic carbons or chiral centers, across the bis-THF skeleton from C-15 through C-24, and C-36, as well as a configuration of threo/trans/threo/trans/erythro and R-S system of S, R, S, R, S, R and R. 15-acetyl guanacone, a natural $O$-monoacetylated guanacone (derivative of guanacone) has previously been isolated from the ethyl acetate extract of Annona Spraguei Saff. seeds, a member of the Annonaceae and elucidated as reported by Bermejo et al. (2005), but not in Annona muricata. This thus confirms the vast availability of possible novel or unidentified acetogenins and anticancer molecules that Annona muricata contains.

\section{Molecular Docking Experiments}

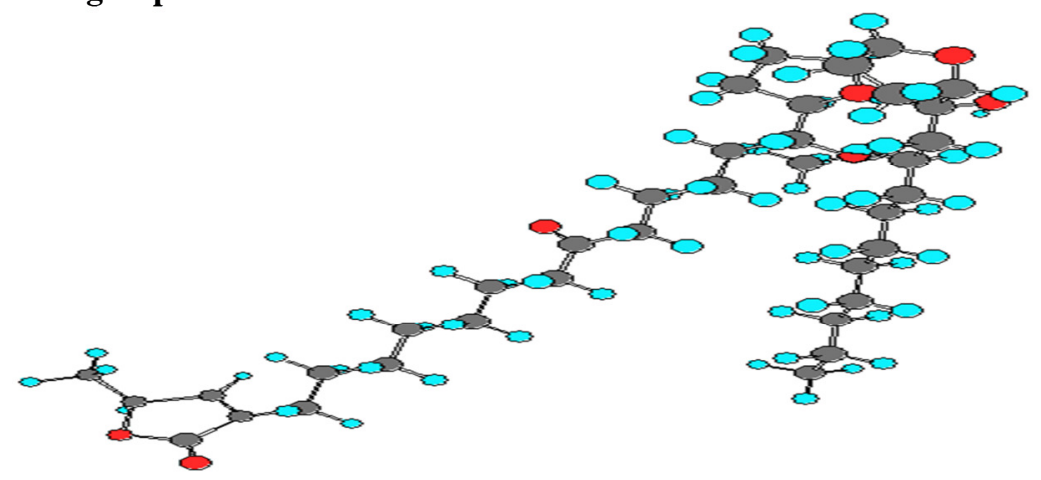

Fig 7. Three-Dimensional structure of 15-acetyl guanacone used for the molecular docking experiments describing a hair-pin track ball presentation.

KINGSLEY, CHUKWUNONSO AGU; NGOZI, PAULINUS OKOLIE; ABIODUN, FALODUN;

OSAYEMWENRE, ERHARUYI ; IGHODARO, IGBE; OLUSOLA, OLALEKAN ELEKOFEHINTI; RICHARD,

OSARO EDOSA; STEPHEN EWEMADE OGHAGBON 

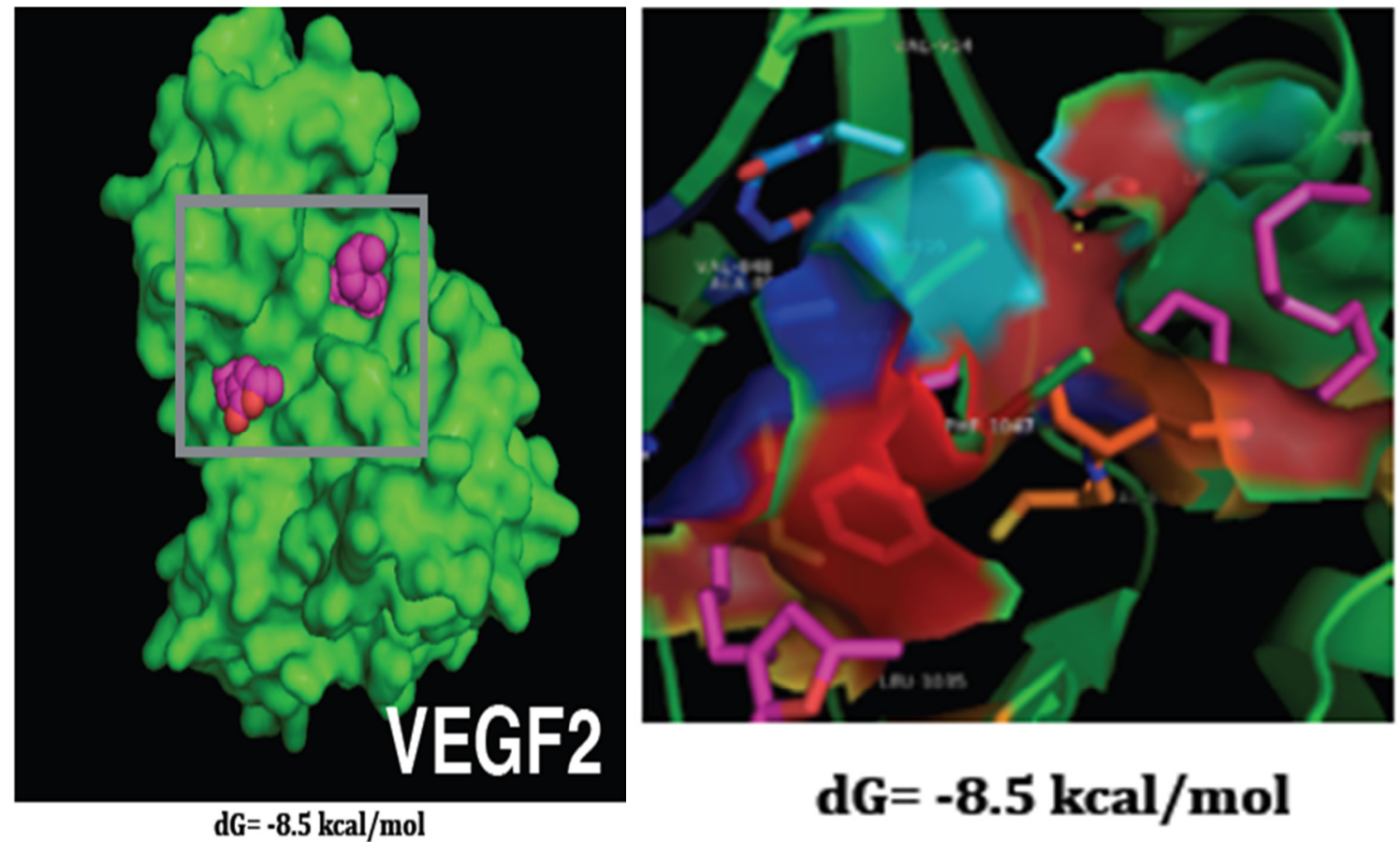

$\mathrm{dG}=-8.5 \mathrm{kcal} / \mathrm{mol}$

Fig 8: Reverse docking experiment showed that 15-acetyl guanacone targets vascular endothelial growth factor 2 (VEGF 2). Molecular docking predicted that 15-acetyl guanacone binds at the active site of vascular endothelial growth factor 2 (VEGF 2) with an affinity of $-8.5 \mathrm{kcal} / \mathrm{mol}$.

Binding Affinity (kcal/mole) of Known VEGF2 Inhibitors<smiles>CNC(=O)c1cc(Oc2ccc(NC(=O)Nc3ccc(Cl)c(C(F)(F)F)c3)c(F)c2)ccn1</smiles>

Fig 9: Regorafenib (Stivarga $\left.{ }^{\circledR} ;-10.60 \mathrm{kcal} / \mathrm{mole}\right)$ and Motesanib® $(-11.20 \mathrm{kcal} / \mathrm{mole})$. 

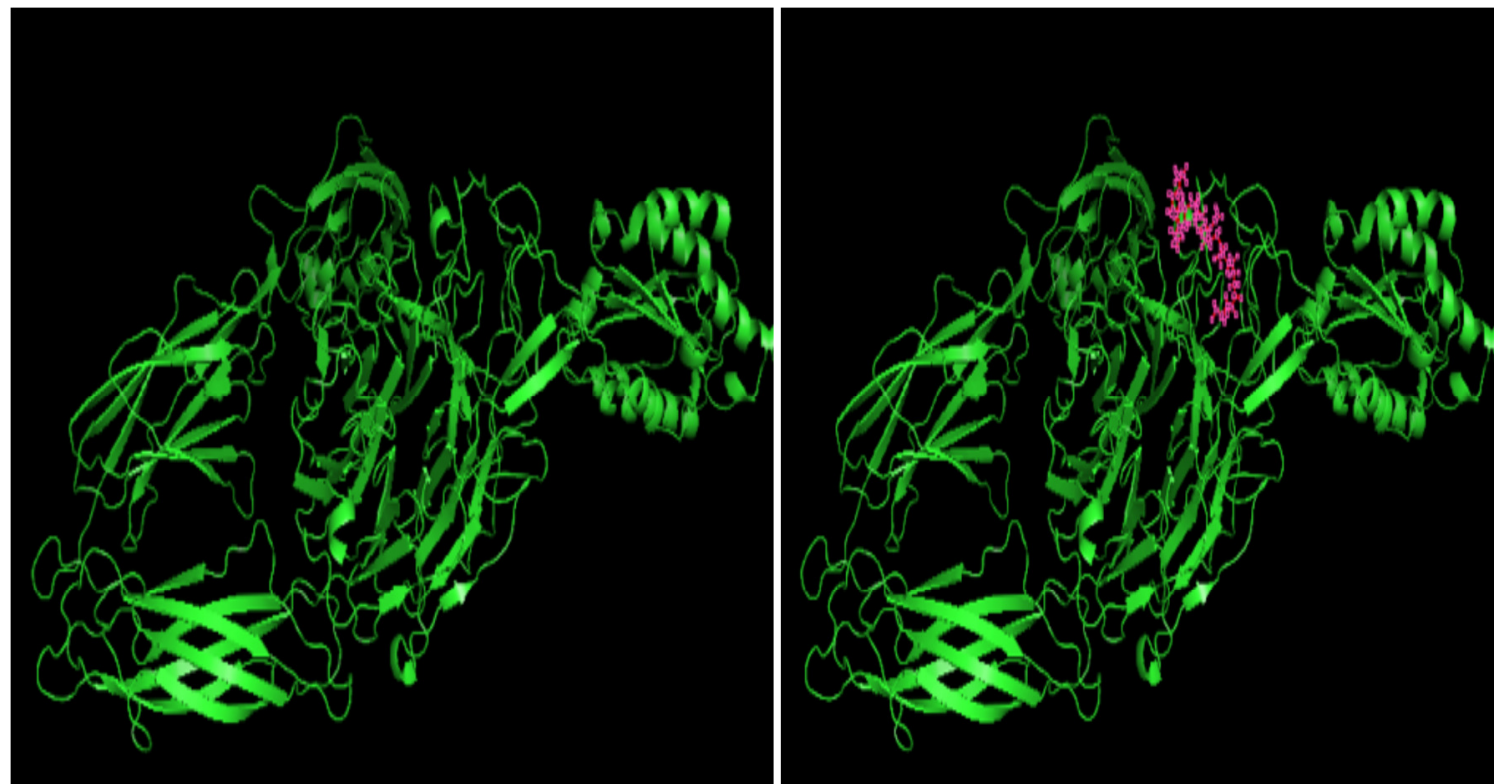

Fig10. 3D structure of human $\beta 2$ integrin. Binding pose of 15 -acetylguanacone with human integrin with a binding energy of $-6.8 \mathrm{kcal} / \mathrm{mole}$.

Data from the molecular docking experiments revealed that 15-acetyl guanacone targets and bind to vascular endothelial growth factor 2 (VEGF2), one of the growth factors required by cancer cells for neovascularization during invasion and metastasis, and also $\beta 2$ integrin. This, implies that one of the key mechanisms of action of Annona muricata (15-acetyl guanacone) is through the inhibition of the formation of new vascular network utilized by the malignant cells, starving their new colonies of nutrients and thus, inhibition of the invasion of neighbouring tissues. Cell-cell adhesion is also blocked. The high mortality and morbidity attributed to cancer is as a result of its ability to metastasize and invade new tissues, cutting nutrient supplies to these tissues. Thus, the targeting and inactivation of the VEGF2 and $\beta 1$ integrin proteins of neoplastic cells affords a formidable attempt in the fight against malignancy.

Acknowledgements: Thanks are due to Dr. Kelly Oriakhi of the Department of Biochemistry, University of Benin, Nigeria and Dr. Farzana of the International Center Chemistry and Biological Sciences, Karachi, Pakistan for the assistance in obtaining the spectra. Professor F. O. Obi, of the Department of Biochemistry, University of Benin and Mr. Kingsley, Mrs. Obi and Mrs. Florence Adesina of the Faculty of Pharmacy, University of Benin, Nigeria, are highly appreciated for their roles in this work especially during the phases of compound isolation and purification using the preparatory thin layer chromatography.

\section{REFERENCES}

Alali, FQ; Liu, XX; McLaughlin, JL (1999). Annonaceous acetogenins: Recent progress. Journal of Natural Products 62 (3): 504-540.

Barrachina, I; Royo, I; Baldoni HA; Chahboune, N; Suvire, F; DePedro, N; Zafra-Polo, MC; Bermejo, A; El Aouad, N; Cabedo, N; Saez, J; Tormo, JR; Enriz, RD; Cortes, D (2007). New antitumoral acetogenin 'guanacone type' derivatives: Isolation and bioactivity. Molecular dynamics simulation of diacetyl-guancone. Bioorgnic and Medicinal Chemistry 15: 43694381.

Bermejo, A; Figadère, B; Zafra-Polo, MC; Barrachina, I; Estornell, E; Cortes, D (2005). Acetogenins from Annonaceae. Recent progress in isolation, synthesis, and mechanisms of action. Natural Product Report 22: 269-303.

Gallardo, T; Saez, J; Granados, H; Tormo, JR; Velez, ID; Brun, N; Torres, B; Cortes, D (1998). 10Oximeguanacone, the first nitrogenated acetogenin derivative found to be a potent inhibitor of mitochondrial complex I. Journal of Natural Products 61: 1001-1005.

Gavanji, S; Larki, B; Mortazaeinezhad, F (2014). Bioinformatic prediction of interaction between flavonoids of propolis of honey bee and envelope glycoprotein GP120. International 
Journal of Scientific Research in Environmental Sciences 2: 85-93.

Gupta, A; Pandey, S; Shah, DR; Yadav, JS; Seth NR (2011). Annonaceous Acetogenins: The Unrevealed Area for Cytotoxic and Pesticidal Activities. Systematic Reviews in Pharmacy 2: 2.

Kojima, N; Tanaka, T (2009). Medicinal Chemistry of Annonaceous Acetogenins: Design, Synthesis, and Biological Evaluation of Novel Analogues. Molecules 14: 3621-3661.

Morre, DJ; Cabo, RD; Farley, C; Oberlies, NH; McLaughlin, JL (1995). Mode of bullatacin. A potent new antitumor acetogenin: Inhibition of NADH oxidase activity of HELA and HL-60, but not liver plasma membranes. Life Science 56: 343.
Oberlies, NH; Chang, CJ; McLaughlin, JL (1997b). Structure-activity relationships of diverse Annonaceous Acetogenins against multidrug resistant human mammary adenocarcinoma (MCF-7/Adr). J Med Chem. 40(13): 2102-2106.

Oberlies, NH; Croy, VL; Harrison, ML; McLaughlin, JL (1997a). The annonaceous acetogenin bullatacin is cytotoxic against multidrug-resistant human mammary adenocarcinoma cells. Cancer Letter 115: 73-79.

Takada, M; Kuwabara, K; Nakato, H; Tanaka, A; Iwamura, H; Miyoshi, H (2000). Definition of crucial structural factors of acetogenins, potent inhibitors of mitochondrial complex I. Biochimica et Biophysica Acta (BBA) Bioenergetics 1460 (2-3): 302-310. 